\title{
Role of the domestic dog as a reservoir host of Leishmania donovani in eastern Sudan
}

\author{
Mo'awia M Hassan*1, Omran F Osman², Fathi MA El-Raba'a², \\ Henk DFH Schallig ${ }^{3}$ and Dia-Eldin A Elnaiem ${ }^{4}$
}

Address: ${ }^{1}$ Department of Epidemiology, Tropical Medicine Research Institute, National Centre for Research, Ministry of Science and Technology, PO Box 1304, Khartoum, Sudan, ${ }^{2}$ Department of Zoology, University of Khartoum, Khartoum PO Box 321, Sudan, ${ }^{3}$ Royal Tropical Institute (KIT), Biomedical Research, Meibergdreef 39, 1105 AZ Amsterdam, the Netherlands and ${ }^{4}$ NIAID, NIH, 12735 Twinbrook PKWY, Rockville, Maryland, 20852-8132, USA

Email: Mo'awia M Hassan* - moawia65@hotmail.com; Omran F Osman - omrann@hotmail.com; Fathi MA ElRaba'a - fathielrabaa@yahoo.com; Henk DFH Schallig - H.Schallig@kit.nl; Dia-Eldin A Elnaiem - elnaiemd@niaid.nih.gov

* Corresponding author

Published: 17 June 2009

Parasites \& Vectors 2009, 2:26 doi:10.1186/1756-3305-2-26
Received: 12 February 2009

Accepted: 17 June 2009

This article is available from: http://www.parasitesandvectors.com/content/2/I/26

(C) 2009 Hassan et al; licensee BioMed Central Ltd.

This is an Open Access article distributed under the terms of the Creative Commons Attribution License (http://creativecommons.org/licenses/by/2.0), which permits unrestricted use, distribution, and reproduction in any medium, provided the original work is properly cited.

\begin{abstract}
Background: The study aims to determine the role of domestic dogs in transmission of visceral leishmaniasis in eastern Sudan. A cross-sectional survey was conducted in 10 villages along the River Rahad in eastern Sudan to elucidate the role of domestic dogs (Canis familiaris, Linnaeus, 1758) as a reservoir host of Leishmania donovani. In this study, 87 dogs were screened for infection by Leishmania donovani. Blood and lymph node samples were taken from 87 and 33 dogs respectively and subsequently screened by the Polymerase Chain Reaction (PCR) and Direct Agglutination Test (DAT) test. Additional lymph node smears were processed for microscopy and parasite culture. Host preference of the visceral leishmaniasis (VL) vector in the area, Phlebotomus orientalis, and other sandflies for the Nile rat (Arvicanthis niloticus, É. Geoffrey, 1803), the genet (Genetta genetta, Linnaeus, 1758), the mongoose (Herpeistes ichneumon, Linnaeus, 1758), and the domestic dog were determined by counting numbers of sand flies attracted to CDC traps that were baited by these animals.
\end{abstract}

Results: DAT on blood samples detected anti-Leishmania antibodies in 6 samples (6.9\%). Two out of 87 (2.3\%) blood samples tested were PCR positive, giving an amplification product of $560 \mathrm{bp}$. The two positive samples by PCR were also positive by DAT. However, none of the $33 \mathrm{lymph}$ nodes aspirates were Leishmania positive when screened by microscopy, culture and genus-specific $P C R$. The dog-baited trap significantly attracted the highest number of $P$. orientalis and sand fly species $(P<0.00 \mathrm{I})$. This was followed by the Egyptian mongoose baited trap and less frequently by the genet baited trap.

Conclusion: It is concluded that the results obtained from host attraction studies indicate that dog is more attractive for $P$. orientalis than Egyptian mongoose, common genet and Nile rat. 


\section{Background}

Visceral leishmaniasis (kala-azar), caused by members of the Leishmania donovani complex is one of the most important parasitic diseases, especially in Sudan, India and Nepal [1]. It is estimated that visceral leishmaniasis affects more than 100 million people worldwide [2]. In the past few years, VL claimed the lives of thousands of people in eastern and southern parts of Sudan $[3,4]$. Previous studies have showed that there were more than Leishmania species causing VL in Sudan $[5,6]$, but more recently molecular investigations revealed that $L$. donovan $i$ is the only causative agent of VL in East Africa [7]. In most VL endemic areas of Sudan, the only vector of $L$. donovani is Phlebotomus orientalis [8], which is associated with Acacia seyal/Balanities aegyptiaca woodland that grow on black cotton soils [9]. The exception to this is a small focus of $\mathrm{VL}$ in the Kapoeta area of south Sudan, where P. martini is suspected to be the main vector of VL [10].

In the New World, VL is a zoonotic disease, involving different canine species, especially the domestic dog and the two fox species, Lycalopex vetulus (Lund, 1842) and Cerdocyon thous (Linnaeus, 1766) $[11,12]$. In the Mediterranean regions of the South Europe and North Africa, the main reservoir hosts are the domestic dogs and the three fox species; Vulpes vulpes (Linnaeus, 1758), V. Corsac (Linnaeus, 1768) and $V$. zerda (Zimmermann, 1780) [reviewed by Ashford and Bettni, [13,14]]. It is noteworthy that in all VL zoonotic foci, where the dog is considered as the primary reservoir host, the disease is caused by L. infantum [15] or L. chagasi [16].

In East Africa, including Sudan, the transmission of $L$. donovani, is thought to be anthroponotic [17], especially during epidemic situations although zoonotic foci were encountered in these epidemics [14]. Apparently, the zoonotic transmission of $\mathrm{VL}$ in the region was initially observed following outbreaks of VL among people that camped in un-inhabited areas of eastern and southern Sudan [18]. We also observed high infection rates of $L$. donovani in uninhabited woodland areas in Dinder National Park (DNP) and provided evidence that in this habitat the Egyptian mongoose (Herpestes ichneumon) may be a primary reservoir host of the parasite [19]. In a village habitat, infection in dogs was reported from the Atbara River area in eastern Sudan [20,21].

Dereure et al. [20] were the first to report firm evidence that the domestic dog may be an important reservoir of Leishmania donovani in eastern Sudan and other part of east Africa. These authors showed that up to 5.9\% of dogs may be infected by the parasite. However, the study was focused in one village in the northern part of the VL endemic zone of eastern Sudan and did not include a description of the population density of dogs and their possible interaction with the vector.

In this study, we conducted a cross sectional survey to determine the population density of dogs and their infection rates with $L$. donovani in 10 villages along the Rahad River, which lies at the southern part of the endemic zone of visceral leishmaniasis in eastern Sudan. We also compared host attractiveness of $P$. orientalis and other sandflies to the dog and other potential reservoir hosts of $L$. donovani; namely the Egyptian mongoose (Herpestes ichneumon), the Genet (Genetta genetta) and the Nile Rate (Arvicanthis niltoticus).

\section{Results \\ Dog population and their rates of infection with L.donovani}

The total number of dogs recorded in the study villages was 243. The density of dogs was one dog per Hausa village, 96 dogs per Masaleet village and 18 dogs per village in the whole study area. Considering a total village surface area of 6 kilometers of the study area, we estimated an average density of $24.3 \mathrm{dogs} / \mathrm{km}^{2} /$ village.

Of the 87 blood samples, 6 (6.9\%) were found to be DAT positive, but none of the 3 dogs with skin ulcers showed seropositivity.

All 33 impression smears made from lymph node aspirates from dogs during this survey were microscopically negative for the presence of Leishmania amastigotes. Also, the lymph node aspirates in the culture media were found to be all negative.

Using Leishmania specific-PCR on 87 dog blood samples from the study area, we detected two positive for Leishmania DNA from Um Kura'a and Um Adara villages, with a band size of $560 \mathrm{bp}$. Interestingly, the PCR positive sample was positive with DAT tests and all $33 \mathrm{dog}$ lymph node samples screened by PCR were found negative for Leishmania infection.

\section{Attraction of different sandfly species to animal baited traps}

The mean numbers $(M \pm S E)$ of different sandfly species attracted to animal baited traps are presented in Table 1. The dog baited trap significantly attracted the highest number of all sandflies species $(\mathrm{P}<0.001)$, except $S$. bedfordi which was significantly attracted in higher number to rat baited trap $(\mathrm{P}<0.001)$. The second animal baited trap which collected more sandflies species (including P. orientalis) was the trap baited with Egyptian mongoose, followed by genet baited trap. 
Table I: Mean number of sandfly species collected by animal baited traps in Dinder National Park (DNP), eastern Sudan during May 2002.

\begin{tabular}{|c|c|c|c|c|c|c|c|c|}
\hline \multirow[t]{2}{*}{ Baited trap } & \multicolumn{7}{|c|}{$M \pm$ S.E No of female sandflies collected per light trap } & \multirow[t]{2}{*}{$P$ value } \\
\hline & P. orientalis & P. rodhaini & S. clydei & S. Schwetzi & S. africana & S. bedfordi & S. antennatus & \\
\hline Control & $0.4 \pm 0.16$ & $0.1 \pm 0.1$ & $2.2 \pm 0.49$ & $3.11 \pm 1.16$ & $0.9 \pm 0.3$ & $2.7 \pm 0.31$ & $0.1 \pm .0 .1$ & 0.005 \\
\hline Dog & $228.8 \pm 53.5$ & $29.7 \pm 4.74$ & $99.1 \pm 17.16$ & $83.9 \pm 12.72$ & $6.4 \pm 0.9$ & $14.3 \pm 2.09$ & $1.24 \pm 0.7 \mid$ & $<0.001$ \\
\hline Mongoose & $63.9 \pm 12.1$ & $5.88 \pm 1.13$ & $21.88 \pm 3.98$ & $21.0 \pm 12.75$ & $2.75 \pm 0.53$ & $12.5 \pm 2.19$ & $0.5 \pm 0.72$ & $<0.001$ \\
\hline Genet & $17.4 \pm 3.72$ & $3.2 \pm 1.05$ & $8.6 \pm 1.9$ & $6.8 \pm 1.78$ & $3.7 \pm 0.83$ & $0.3 \pm 0.21$ & $0.5 \pm 0.72$ & $<0.001$ \\
\hline Nile rat & $2.6 \pm 0.56$ & $1.0 \pm 0.33$ & $2.8 \pm 0.39$ & $2.5 \pm 0.39$ & $11.9 \pm 1.8$ & $2.1 \pm 1.1$ & $0.7 \pm 0.26$ & $<0.001$ \\
\hline
\end{tabular}

Table 2 shows the $\mathrm{M} \pm$ SE numbers of female and male $P$. orientalis collected in DNP by traps baited with different animals. Using one-way ANOVA, the two sexes were found to be attracted significantly in higher numbers to dog baited trap (female, $228.8 \pm 53.5$; male, $22.9 \pm 4.98$ ) compared with animal traps $(\mathrm{P}<0.001$ for both $)$. The second most attractive animal to $P$. orientalis was the Egyptian mongoose, followed by the genet. There was a significant difference between the numbers of male and female sandflies attracted by each of the dog, the mongoose, the genet $(P=0.001)$ and the rat $(P=0.028)$.

\section{Discussion}

Knowledge of the reservoir hosts and their population density is an important pre-requisite for understanding the epidemiology and designing control programmes of zoonotic visceral leishmaniasis. However, in Sudan and other places in East Africa, the zoonotic transmission cycle of $L$. donovani is not well understood [17]. Nonetheless, recent evidence indicated the existence of a sylvatic zoonotic cycle involving the Egyptian mongoose as a potential reservoir host in uninhabited woodlands of Dinder National Park [19]. Other studies also showed high infection rates of $L$. donovani in dogs of one village in the Atbara area of eastern Sudan [20,21]. Although clearly indicating that the domestic dog may be an important reservoir host of L. donovani in eastern Sudan, these studies were limited to one village and did not address the population density of dogs and their relationship with the vector.
Our results showed that $6.9 \%$ of the dogs in the study area were serologically positive for $L$. donovani infection. This is similar to the serological finding reported by Dereure et al. [20] who found that $8 \%$ of dogs were seropositive in Atbara River area in eastern Sudan and much lower than that reported from VL endemic areas in the Mediterranean region [reviewed in [22]]. The seroprevalence found in the present study does not match the results obtained from the parasitological and molecular tests [20]. These differences may be due to timing of sampling following the transmission season. Alternatively, our results may indicate the existence of some sort of an asymptomatic nature of infection among dogs in the area.

A major observation in our study is that dog density in the eastern Sudan is quite low and there is a clear variation in dog ownership by members of different tribes. We observed that most of the people that owned dogs belong to Masaleet tribes. In contrast, and probably for religious reasons, the Hausa keep few or no dogs at all. This observation is interesting since the Masaleet tribe has been reported to have the highest VL infection in the area $[23,4]$. Future work should be done to investigate dog ownership as a major risk factor of VL transmission among the Masaleet people, besides other socioeconomic, ecological and genetic factors [23,4].

Previous studies on natural attraction of sandflies to human and different animal hosts were conducted on the vector of Lutzomyia longipalpis [24,25]. Such studies revealed that most of sandflies in both New and Old World species have a varying degree of host preference,

Table 2: Mean number of males and females Phlebotomus orientalis collected by animal baited traps in Dinder National Park (DNP), eastern Sudan during May 2002.

\begin{tabular}{lllll}
\hline Animal trap & & M S.E No of $P$. orientalis collected per animal trap & $P$ value \\
\hline & Female & Male & Total & 1.00 \\
Control & $0.4 \pm 0.16$ & $0.4 \pm 0.22$ & $0.8 \pm 0.2$ & 0.001 \\
Dog & $228.8 \pm 53.5$ & $22.9 \pm 4.98$ & $257.7 \pm 58.38$ & 0.001 \\
Mongoose & $63.88 \pm 12.08$ & $9.88 \pm 2.43$ & $73.29 \pm 13.18$ & 0.001 \\
Genet & $17.4 \pm 3.72$ & $2.80 \pm 0.7$ & $20.2 \pm 3.94$ & 0.028 \\
Nile rat & $2.6 \pm 0.56$ & $1.0 \pm 0.37$ & $3.6 \pm 0.7$ & $<0.001$ \\
P value & $<0.001$ & $<0.001$ & & \\
& & & & \\
\hline
\end{tabular}


and hence they are opportunistic feeders $[26,27]$. This can be observed, in the feeding behaviour of the sandfly $P$. argentipes which is predominantly zoophilic in lowland areas and anthropophilic in the highlands [27]. Most sandfly species feed on a wide range of hosts. In India it has been observed that $P$. papatasi prefer to feed on human blood; however, it has also been observed feeding on other animal species, [28]. In a longitudinal host preference study, Montoya-Lerma and Lane [29] found that the sandfly Lutzomyia evansi was attracted in great numbers to human compared with dogs or oppossum which are the known reservoirs.

Although the body mass of an animal might affect the attractively of sand flies i.e. larger animals may attract more sand flies than smaller animals (giving different amount of $\mathrm{CO}_{2}$, odours etc). Interestingly, the results obtained in this study showed clear preference of $P$. orientalis to dog over the mongoose, genet and Nile rat. Our data on the body mass of the animals used did not show any correlation with the number of attracted flies ( $\mathrm{P}=$ $0.074)$. This finding may give evidence that $P$. orientalis is in close association with the domestic dogs inside villages of eastern Sudan. The number of $P$. orientalis attracted to the Egyptian mongoose is significantly higher when compared with that of the genet and the rat. This result supports our previous finding that the mongoose may be an important sylvatic reservoir for $L$. donovani by [19].

The number of $P$. orientalis attracted to A. niloticus was few possibly indicating that $A$. niloticus is not a reservoir host of $L$. donovani although it was found infected with visceralizing parasites by a few workers [30,31,19]. These findings support the suggestion that A. niloticus could be an accidental host which does not play an important role in maintaining and circulating the parasites in the area [19]. Moreover, our field observations showed that the relative abundance of the animals used was in the order: Arvicanthis niloticus, dog, Egyptian mongoose and common genet. Based on this, it would be difficult to categorize reservoir hosts on abundance due the seasonal variation in population sizes.

Attractiveness data from humans would have been very useful for comparison with the present obtained results. Nevertheless in this study, human baited collection was not possible because of ethical considerations. Data on attractiveness of human to $P$. orientalis from the same study area has been published by Elnaiem et al. [32]who showed these flies were attracted in higher numbers to human without bednets than those using untreated bednets $(\mathrm{P}=0.001)$.

\section{Conclusion}

In conclusion, although our investigations showed low seropositivity and low positive PCR results for Leishmania infection nevertheless, the attractiveness data suggests that dog seems to play a role in the transmission dynamics of the VL. Additional work is needed to reflect the actual infection rate of Leishmania in dogs. Comparative enzymatic and molecular characterization of the parasite found in dogs, VL patients and sandflies is imperative for understanding the dynamics of the transmission of VL to set strategies for future control programmes.

\section{Methods}

\section{Study area}

This study was carried out during May 2002 in an endemic area of visceral leishmaniasis in eastern Sudan in 10 villages along the river Rahad, adjacent to the north east edge of Dinder National Park (DNP). The villages were; Ebiek, Um Salala, Um Salala Hug, Ein-Elgamel, Um Kakar Hug, Um Kura'a, Batta, Shateeb, Hilat Hashim, Um Adara (Gedaref State) (Fig. 1). The ecology of the study area is

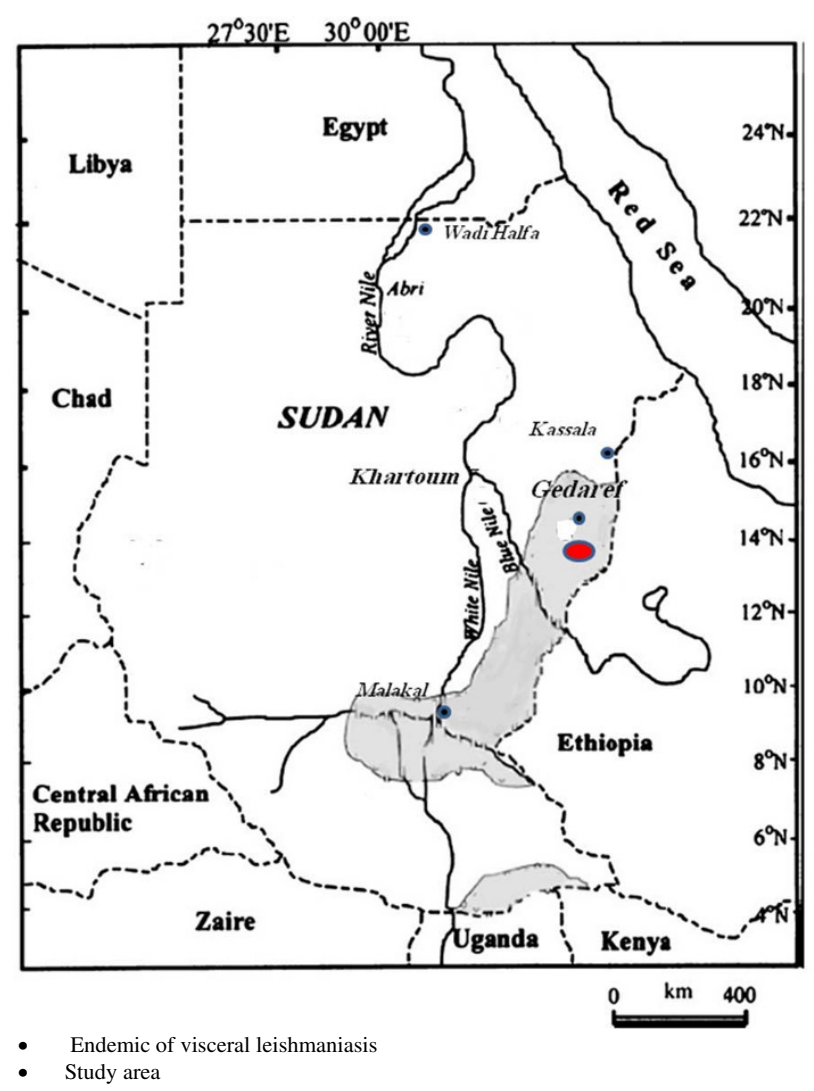

Figure I

Map showing the location of the study area in eastern Sudan. I. The Endemic area is the area represented by the grey colour and not black dot. 2 . The study area is in red colour and not black dot. 
described by Elnaiem et al. [4]. The land is flat, but in many places it is interrupted by the seasonal rivers and tributaries and little ground surface water collection. The soil is mainly chromic vertisol (black cotton soil), with few fractions of alluvial clays, sandy and silts soil known as "Azaza".

The climate of the areas is tropical continental with an estimated annual rainfall of $1000 \mathrm{~mm}$. The year may be divided into dry (November-May), and rainy season (June-October). The average minimum-maximum temperatures of the area are $21-37.3^{\circ} \mathrm{C}$ and $18.3-40^{\circ} \mathrm{C}$ (Gedaref meteorological Station; 2001).

The vegetation of the area is dominated by savannah tree species such as Acacia seyal (Taleh), A. senegal (Hashab), Balanites aegyptiaca (Hig-leeg) and Ziziphus spina-christie (Sidir). The villages have fewer vegetation densities than DNP and are surrounded by cultivated fields of Dura (Sorghum purpura), Dokhun (Pennisetum typhodium), Sesame (Seasmum orientalis) and Groundnuts (Arachis hpogaea).

The villages have diverse human populations that are dominated by Fallata", "Masalit", "Hausa", "Burgo" and "Fur" tribes of western Sudan and West African ethnic groups. People of the villages live in African huts constructed of wood, bamboo and grass [4].

\section{Determination of infection with visceralizing Leishmania parasites among the dog population in the area Screening of dogs for prevalence of $L$. donovani}

A cross-sectional survey was done during May 2002 to determine the population density of dogs in the villages and determine their rates of infection with $L$. donovani. Initially, we conducted a census of all domestic dogs in the 10 villages and recorded their descriptive information (age, dog function, duration in the endemic area of $\mathrm{VL}$ ) and signs of canine visceral leishmaniasis (CVL) in a standard questionnaire form. Signs of CVL were recorded as described by Ferrer [33].

A total of 87 dogs were screened for the presence of $L$. donovani infection. The main criterion for including a dog in this screening was based on its age (more than six months) and that it lived at least one transmission season in the endemic area of VL. Blood samples from the ear of each dog were blotted on a filter paper (Whattman \# 3) for subsequent serological test and PCR. Filter papers were air-dried for 3 hours. To avoid contamination, each sample was transferred separately into small plastic bag. The samples were stored at $4{ }^{\circ} \mathrm{C}$ until used in the PCR and DAT tests.

Thirty three aspirates of popliteal lymph nodes were aseptically taken by sterile syringes from dogs that were either
$=2$ years old and/or had an enlarged lymph node at time of inspection, and individually transferred on filter papers (Whattman \# 3), air-dried for about $3 \mathrm{hr}$ and stored at $4{ }^{\circ} \mathrm{C}$ for subsequent PCR testing. Impression smears of lymph nodes aspirates were also made on glass slides, stained by Giemsa's stain and then examined for presence of Leishmania amastigotes. Additional samples of the lymph-node fluid were inoculated into a NNN media supplemented with antibiotics; $5 \mathrm{mg} / \mathrm{ml}$ Penicillin and Streptomycin and then kept at room temperature for 7 days. Cultures were then taken to the laboratory in Khartoum and maintained for 45 days. During this period, cultures were checked once every three days for presence of Leishmania promastigotes.

\section{Direct agglutination Test (DAT) and PCR detection of Leishmania DNA in lymph node and blood samples}

The DAT test was performed on the blood samples, as described previously by El-Harith et al. [34] and Zijlstra et al. [35]. Briefly, serum samples were diluted in physiological saline $(0.9 \% \mathrm{NaCl})$ containing $0.8 \%$ b-mercaptoethano. Two-fold dilutions of the sera were made, starting at a dilution of 1:100 and going up to a maximum serum dilution of 1:102,400. Freeze-dried DAT antigen (stained L. donovani promastigotes) produced by KIT Biomedical Research was reconstituted with physiological saline. Fifty $\mu \mathrm{L}$ of DAT antigen solution (concentration of $5 \times 10^{7}$ parasites per $\mathrm{ml}$ ) was added to each well containing $50 \mu \mathrm{l}$ of diluted serum. The results were read after 18 hours of incubation at ambient temperature. The cut-off value was established considering the titres obtained in samples from negative controls therefore; a sample was considered positive if it had a titre of 1:800.

DNA was extracted from all lymph node (33 samples) and blood samples (87 samples) and then subjected to PCR testing as described by Osman et al. [36]. Briefly, $5 \mu \mathrm{l}$ was added to $45 \mu \mathrm{l} \mathrm{PCR} \mathrm{mix} \mathrm{containing} 10$ Tris- $\mathrm{HCl} \mathrm{pH}$ 8.3, 50 $\mathrm{mM} \mathrm{KCl}, 4 \mathrm{mM} \mathrm{MgCL}{ }_{2}, 250 \mu \mathrm{l}$ of each dNTPs, 0.5 unit Taq polymerase, 100 pmol primer R174 (5' GGTTCCTTTCCTGATTTAGG 3') and 100 pmol primer R798 (5' GGCCGGTAAAGGCCGAATAG 3'). Samples were preincubated for $5 \mathrm{~min}$ in $50^{\circ} \mathrm{C}$ followed by initial denaturation at $94^{\circ} \mathrm{C}$ for $10 \mathrm{~min}$ and 38 cycle consisting of denaturation at $94^{\circ} \mathrm{C}$ for $75 \mathrm{sec}$, annealing at $60^{\circ} \mathrm{C}$ for $1 \mathrm{~min}$ and extension at $72^{\circ} \mathrm{C}$ for $2 \mathrm{~min}$. Amplified DNA was then visualized on $2 \%$ agarose gel and 100 bp DNA molecular weight ladder were used as a markers. A band of $560 \mathrm{bp}$ is considered as positive for $L$. donovani DNA.

DNA extracted from Promastigotes of $L$. donovani (MHOM/SD/68/1S) cultured in vitro was used as a positive control and PCR water free of DNA was used as a negative control for PCR. 


\section{Host attractiveness experiments}

Attractiveness of the Nile rat, the domestic dog, the genet and the Egyptian mongoose to $P$. orientalis was investigated in Um kura'a warden camp during May 2002. A host choice experiment was done by placing CDC miniature traps, from which the light bulbs were removed, over 4 cages, each containing one of these mammals. The traps were placed at $5 \mathrm{~cm}$ above each animal. The animal cages varied in dimensions according to the animal sizes. The sizes of the cages used for the dog, mongoose and the genet were the same sizes $\left(40 \times 20 \times 20 \mathrm{~cm}^{3}\right)$ because these three animals have approximately similar sizes. The rat cage was smaller $\left(12 \times 10 \times 8 \mathrm{~cm}^{3}\right)$.

Animals were tested simultaneously, between 18:00 06:00 HR, using un-baited cages (empty cages) as negative controls. The experiment was replicated 10 times and the animals were rotated between different positions to avoid bias resulting from location of trapping site. Each species was represented by one individual that was used for all replicates of the experiments.

Sandflies collected by different animal traps, were preserved in $70 \%$ ethanol and then processed for species identification as described previously $[8,37]$. Numbers of males and female sandflies, from each species, that were attracted to different animals were compared using nonparametric Kruskal-Wallis test within the SPSS software (10.0).

\section{Ethical considerations}

The protocol of the study was ethically approved by the Research Board of the Faculty of Science, University of Khartoum.

\section{Competing interests}

The authors declare that they have no competing interests.

\section{Authors' contributions}

MMH designed the field studies, performed experiments, laboratory analysis, analyzed the data, and help to draft the manuscript. DAE, OFO and FMAE help in designing the field studies and help to draft the manuscript. HSDFH carried out PCR analysis and was involved in the drafting of the manuscript. All authors read and approved the final copy of this manuscript.

\section{Acknowledgements}

We would like to thank Prof. Suad M. Suliman of (TMRI) and Prof. Nasr Eldin A. Mahmoud Dean Faculty of Khartoum College of Medical Sciences who provided financial support for this work. Also, thanks are due to people of the surveyed villages who helped patiently in sample collection. Many thanks to Mr. Breema Musa (Faculty of Science, University of Khartoum), for help and support in fieldwork. This Investigation received financial support from UNICEF/UNDP/World Bank WHO. Special programme for
Research and Training in Tropical Disease (TDR). Grant (Osman: A 4I90 - TDR, WHO).

\section{References}

I. World Health Organization: Annual Report. Geneva 2002.

2. Desjeux P, Piot B, O'Neill K, Meert JP: Co-infections of LeishmanialHIV in south Europe. Med Trop (Mars). 2001, 6 I (2): 187-193.

3. Seaman J, Mercer AJ, Sondorp E: The epidemic of visceral Leishmaniasis in Western Upper Nile, southern Sudan: course and impact from 1984-1994. Int J Epidemiol 1996, 25:862-87I.

4. Elnaiem DA, Schorscher J, Bendall A, Obsomer V, Osman ME Mekkawi AM, Cooner SJ, Ashford RW, Thomson MC: Risk mapping of visceral leishmaniasis: the role of local variation in rainfall and altitude on the presence and incidence of kalaazar in eastern Sudan. Am J Trop Med Hyg 2003, 68: I 0- I7.

5. Ashford RW, Seaman J, Schorcher J, Pratlong F: Epidemic visceral leishmaniasis in southern Sudan: identify and systematic position of the parasite from patients and vectors. Trans $R$ Soc Trop Med Hyg 1992, 86:379-380.

6. Oskam L, Pratlong F, Zijlstra EE, Kroon CCM, Dedet JP, Kager PA, Schonian G, Ghalib HW, Elhassan AM, Meredith SEO: Biochemical and molecular characterization of Leishmania parasites isolated from endemic focus of eastern Sudan. Trans $R$ Soc Trop Med Hyg 1998, 92:120-122.

7. Jamjoom MB, Ashford RW, Bates PA, Chance ML, Kemp SJ, Watts PC, Noyes HA: Leishmania donovani is the only cause of visceral leishmaniasis in East Africa; previous descriptions of $L$. infantum and "L. archibaldi" from this region are a consequence of convergent evolution in the isoenzyme data. Parasitology 2004, 129:399-409.

8. Elnaiem DA, Hassan KH, Ward RD, Miles MA, Frame IA: Infection rates of Leishmania donovani in Phlebotomus orientalis from visceral Leishmaniasis focus eastern Sudan. Ann Trop Med Parasitol 1998, 92:229-232.

9. Elnaiem DA, Conners S, Thmoson M, Hassan MM, Hassan KH, Aboud MA, Ashford RW: Environmental determinants of the distribution of Phlebotomus orientalis in Sudan. Ann Trop Med Parasitol 1998, 92:877-887.

10. Minter DM, Wijers DJB, Heisch RB, Manson-Bahr PEC: Phlebotomus martini-a probable vector of kala-azar in Kenya. Br Med J 1962 , ii:835.

II. Lainson R: The American Leishmaniasis: some observations on their ecology and epidemiology. Trans $R$ Soc Trop Med Hyg $1983,77: 569-596$.

12. Rodrigues CA, Batista LF, Teixeira MC, Pereira AM, Santos PO, de Sa Oliveira GG, Freitas LA, Veras PS: Peripheral blood mononuclear cell supernatants from asymptomatic dogs immunized and experimentally challenged with Leishmania chagasi can stimulate canine macrophages to reduce infection in vitro. Vet Parasitol 2007, | 43: 197-205.

13. Ashford RW, Bettini S: Ecology and epidemiology: Old World. In The Leishmaniasis in Biology and Medicine Volume I. Edited by: Peters W, Killick-Kendrick R. London: Academic Press; 1987:365-424.

14. Ashford RW: Leishmaniasis reservoirs and their significance in control. Clin Dermatol 1996, 14:523-532.

15. Gavgani AS, Mohite H, Edrissian GH, Mohebali M, Davies CR: Domestic dog ownership in Iran is a risk factor for human infection with Leishmania infantum. Am J Trop Med Hyg 2002, 67:5II-5I5.

16. Cabrera MA, Paula AA, Camacho LA, Marzochi MC, Xavier SC, da Silva AV, Jansen AM: Canine visceral leishmaniasis in Barra de Guaratiba, Rio de Janeiro, Brazil: assessment of risk factors. Rev Inst Med Trop Sao Paulo 2003, 45:79-83.

17. Desjeux $P$ : The increase in risk factors for leishmaniasis worldwide. Trans R Soc Trop Med Hyg 2001, 95:239-243.

18. Kirk R: Studies on Leishmaniasis in the Anglo-Egyptian Sudan. XII. Attempt to find reservoir hosts. Trans $R$ Soc Trop Med Hyg 1956, 50:169-I77.

19. Elnaiem DA, Hassan MM, Maingon R, Nureldin GH, Mekawi AM, Miles $M$, Ward RD: The Egyptian mongoose, Herpestes ichneumon, is a possible reservoir host of visceral leishmaniasis in eastern Sudan. Parasitology 200I, I 22:531-536.

20. Dereure J, Boni M, Pratlong F, Osman M, Boucheton B, El-Safi S, Feugier E, Musa MK, Daroust B, Dessein A, Dededt JP: Visceral 
Leishmaniasis in Sudan: First identification of Leishmania from dogs. Trans R Soc Trop Med Hyg 2000, 94:I54-I55.

21. Dereure J, El-Safi SH, Bucheton B, Boni M, Kheir MM, Davoust B, Pratlong F, Feugier E, Lambert M, Dessein A, Dedet JP: Visceral leishmaniasis in eastern Sudan: parasite identification in humans and dogs; host-parasite relationships. Microbes Infect 2003, 5: I 103-II08.

22. Baneth G, Koutinas AF, Solano-Gallego L, Bourdeau P, Ferrer L: Canine leishmaniosis - new concepts and insights on an expanding zoonosis: part one. Trends Parasitol. 2008, 24(7):324-330.

23. Khalil EAG, Zijlstra EE, Kager PA, Elhassan AM: Epidemiology and clinical manifestations of Leishmania donovani infection in two villages in an endemic area in eastern Sudan. Trop Med Int Health 2002, 7:35-44.

24. Marrison AC, Ferro C, Tesh RB: Host preference of the sand fly Lutzomyia longipalpis at an endemic focus of American visceral leishmaniasis in Colombia. Am J Trop Med Hyg 1993, 49:68-75.

25. Rebollar-Tellez EA, Hamilton JG, Ward RD: Response of female Lutzomyia longipalpis to host odour kairomones from human skin. Physiol Entomol 1999, 4:220-226.

26. Quinnell RJ, Dye C, Shaw J]: Host preferences of the phlebotomine sandfly Lutzomyia longipalpis (Diptera: Psychodidae) in Amazonian Brazil. Med Vet Entomol 1992, 6:195-200.

27. Lane RP, Pile MM, Amerasinghe FP: Anthropophagy and aggregation behaviour of the sandfly Phlebotomus argentipes in Sri Lanka. Med Vet Entomol 1990, 4:79-88.

28. Namita M, Joshi V, Bansal SK: Host preference pattern of sandflies of Bikaner city. Indian J Med Res 1991, 93:328-329.

29. Montoya-Lerma J, Lane RP: Factors affecting host preference of Lutzomyia evansi (Diptera: Psychodidae), a vector of visceral leishmaniasis in Colombia. Bull Entomol Res 1996, 86:43-50.

30. Hoogstraal H, Heynenman D: Leishmaniasis in Sudan Republic. 30. Final epidemiological Report. Am J Trop Med Hyg 1969, 18:1091-1210.

31. Elhassan AM, Zijlstra EE, Meredith SEO, Ismail A: Identification of Leishmania donovani, using a polymerase chain reaction in patients and animal material from an area of endemic kalaazar in the Sudan. Acta Trop 1993, 55:87-90.

32. Elnaiem DA, Elnahas AM, Aboud MA: Protective efficacy of lambdacyhalothrin-impregnated bednets against Phlebotomus orientalis, the vector of visceral leishmaniasis in Sudan. Med Vet Entomol 1999, 13(3):310-314.

33. Ferrer LM: Clinical aspect of canine leishmaniasis. Canine Leishmaniasis update. In Proceedings of the International Canine Leishmaniasis Forum: 28-3I January 1999; Barcelona Edited by: KillickKendrick R. Hoechst Roussel Veterinar; 1999:2-10.

34. El-Harith AE, Kolk AHJ, Leeuwenburg J, Muigal R, Huigen E, Jelsmaa $\mathrm{T}$, Kager PA: Improvement of a direct agglutination test for field studied of visceral leishmaniasis. J Clin Microbol 1988, 26: $1321-1325$.

35. Zijlstra EE, Osman OF, Hofland HWC, Oskam L, Ghalib HW, Elhassan AM, Kager PA, Meredith SEO: Direct agglutination test for diagnosis of visceral leishmaniasis under field condition in the Sudan: comparison of aqueous and freeze-dried antigens. Trans R Soc Trop Med Hyg 1997, 9 I:67I-673.

36. Osman OF, Oskam L, Kroon NC, Schoone G], Khalil EOG, Elhassan AM, Zijlstr EE, Kager PA: Use of PCR for diagnosis of post-kalaazar dermal leishmaniasis. J Clin Microbiol. 1998, 36(6): $1621-1624$.

37. Hassan MM, Elraba'a FM, Ward RD, Maingon RD, Elnaiem DA: Detection of high rates of in-village transmission of Leishmania donovani in eastern Sudan. Acta Trop 2004, 92:77-82.
Publish with Bio Med Central and every scientist can read your work free of charge

"BioMed Central will be the most significant development for disseminating the results of biomedical research in our lifetime. "

Sir Paul Nurse, Cancer Research UK

Your research papers will be:

- available free of charge to the entire biomedical community

- peer reviewed and published immediately upon acceptance

- cited in PubMed and archived on PubMed Central

- yours - you keep the copyright

Submit your manuscript here:

http://www.biomedcentral.com/info/publishing_adv.asp
BiolMedcentral 